\title{
CABARAN KERJAYA KEUSAHAWANAN ATAS TALIAN DALAM KALANGAN PELAJAR UNIVERSITI KEBANGSAAN MALAYSIA
}

\section{CHALLENGES OF ONLINE ENTREPRENEURSHIP CAREER AMONG UNIVERSITI KEBANGSAAN MALAYSIA STUDENTS}

\author{
Helmy Emyrul Mohd Nor Efendee ${ }^{1}$ \\ Fakulti Pendidikan, Universiti Kebangsaan Malaysia, 43600 Bangi, Selangor, Malaysia. \\ (Email: helmyemyrul@gmail.com) \\ Norasmah Othman ${ }^{2}$ \\ Fakulti Pendidikan, Universiti Kebangsaan Malaysia, 43600 Bangi, Selangor, Malaysia. \\ (Email: lin@ukm.edu.my)
}

Received date: 15-07-2019

Revised date: 18-07-2019

Accepted date: $28-08-2019$

Published date: 15-09-2019

To cite this document: Efendee, H. E. M. N., \& Othman, N. (2019). Cabaran Kerjaya Keusahawanan Atas Talian dalam Kalangan Pelajar Universiti Kebangsaan Malaysia. International Journal of Entrepreneurship and Management Practices, 2 (7), 48-53.

DOI: $10.35631 /$ ijemp. 27006

\begin{abstract}
Abstrak: Pembentukan usahawan dalam kalangan pelajar universiti merupakan agenda kerajaan masa kini. Di era Revolusi Industri ke 4, perniagaan atas talian merupakan salah satu kerjaya yang digalakkan untuk diceburi pelajar namun data menunjukkan bilangan yang menceburi bidang ini masih dianggap rendah. Justeru, kajian ini dijalankan bagi tujuan mengenal pasti cabaran kerjaya keusahawanan atas talian mengikut persepsi pelajar Universiti Kebangsaan Malaysia (UKM). Seramai 150 pelajar telah dipilih secara rawak berstrata dilibatkan dalam kajian ini dan soal selidik digunakan sebagai instrumen kajian. Hasil kajian mendapati bahawa terdapat tiga cabaran utama perniagaan atas talian mengikut persepsi pelajar iaitu berkaitan kos perniagaan, komunikasi interpersonal dan kemahiran ICT. Implikasi kajian ini adalah mendorong pihak universiti untuk memperbanyakkan program berkaitan cabaran tersebut agar dapat diatasi pelajar nanti.
\end{abstract}

Kata Kunci: Cabaran, Pelajar Universiti, Perniagaan Atas Talian, Kerjaya Keusahawanan

Abstract: Government has implementing an agenda in creating more entrepreneurs among student in the university. In this Industrial Revolution 4 era, online business is one of the encouraged careers for students, but data shown the number that venture in this area is still considered low. Thus, this study was conducted to identify the challenges of online entrepreneurship career based on Universiti Kebangsaan Malaysia (UKM) student's perceptions. Total of 150 students were 
selected using random sampling and the completed questionnaire used as an instrument for this research. The study found three main challenges of starting an online business according to student's perception which are the cost of business, interpersonal communication and ICT skills. The implications of this research to encourage the university to develop the program to overcome the challenge in the future.

Keywords: Challenges, Students, Business Cost, Interpersonal Communication, ICT Skills

\section{Pengenalan}

Dewasa ini, terdapat ramai usahawan muda mengusahakan produk tempatan hasil daripada gabungan pelbagai sumber bahan mentah yang berkualiti serta diiktiraf pengunaannya. Kaedah pemasaran atas talian menjadi platform utama penyebaran produk kepada sasaran pasaran yang ingin dicapai. Menurut Faradillah Iqmar et al. (2015), penggunaan Internet menjadi pemangkin dalam memperkasakan usahawan dalam kalangan pelajar, terutamanya dalam menceburi perniagaan atas talian. Perniagaan tempatan seperti Elrah Exclusive, Radiusite, CandidSyndrom dan banyak lagi jenama terkenal diusahakan dengan menggunakan kemudahan teknologi bagi mempromosikan produk oleh graduan lepasan Institusi Pengajian Tinggi. Justeru, mereka ini adalah layak dikenali sebagai usahawan muda yang berinovatif dan produktif mempromosikan produk atau servis menerusi Internet, malah golongan usahawan muda ini juga dapat mencorak pembangunan ekonomi negara.

Manakala kemudahan teknologi maklumat yang pantas menjadi keperluan utama dalam kehidupan seharian masyarakat pada masa kini (Nur Yuhainis \& Shuhymee , 2017). Sejak kebelakangan ini, perniagaan atas talian telah membawa satu perubahan yang besar terhadap sistem jual beli yang lebih mudah dan selamat sebagai contoh jenama-jenama fesyen menggunakan laman sesawang dan media sosial untuk mempromosikan pakaian dan pembayaran melalui platform yang lebih selamat. Perniagaan atas talian merupakan satu medium perniagaan yang lebih mudah diuruskan berbanding penjualan produk dan perkhidmatan di kedai fizikal atau secara tradisional. Walau bagaimanapun, pelajar universiti yang terdedah dengan pelbagai program keusahawanan dilihat tidak berminat menceburi keusahawanan secara talian atas faktor kekurangan kemahiran teknikal (Gusniar et al. 2014). Ini merupakan cabaran individu untuk menguasai kemahiran ICT bagi memenuhi kepentingan perniagaan atas talian. Oleh itu, kejayaan penglibatan dalam keusahawanan atas talian juga bergantung kepada kos perniagaan, kepentingan komunikasi interpersonal dan kemahiran ICT.

\section{Kajian Literatur}

\section{Cabaran Keusahawanan Atas Talian}

Pada era revolusi industri 4.0 masa kini, perniagaan atas talian merupakan keperluan utama kepada pengusaha untuk menyiapkan diri bersaing dengan produk tempatan lain dengan mempromosikan produk kepada pelanggan dengan menggunakan kos pemasaran yang rendah. Namun terdapat cabaran untuk memaksimumkan keuntungan melalui perniagaan atas talian ini. Usahawan perlu menempuh pelbagai dugaan dan cabaran bagi menjadi pilihan utama di hati pelanggan. Dalam konteks cabaran keusahawanan, teori tingkah laku terancang (Planned- Behaviour Theory) Azjen (1991) menekankan sikap terhadap sesuatu perkara merupakan halangan kepada kejayaan khususnya dalam bidang keusahawanan. Ini adalah kerana sikap merupakan sebahagian daripada 
proses pembentukan tingkah laku manusia yang sebenar. Menurut Amirul \& Mujaheed (2018), cabaran utama usahawan di Malaysia adalah persaingan yang kian mencabar dan mendesak kerana mereka perlu memenuhi kehendak pelanggan yang mengikuti peredaran masa dan bersaing dalam industri yang penuh dengan pesaing berpengalaman. Selain itu, peranan Institusi Pengajian Tinggi (IPT) untuk melahirkan lebih ramai usahawan siswazah memberi tekanan dan memaksa pelajar untuk menceburi bidang perniagaan berbanding kerjaya yang ingin diceburi. Fenomena ini adalah selaras dengan objektif ke empat Kementerian Pengajian Tinggi (KPT) untuk menghasilkan ramai graduan yang kompeten untuk memenuhi keperluan guna tenaga negara dan antarabangsa dengan sasaran $75 \%$ graduan mendapatkan pekerjaan dalam bidang relevan dalam tempoh enam bulan selepas tamat pengajian (KPT, 2017).

\section{Kos Perniagaan}

Cabaran usahawan merancang perniagaan yang melibatkan kos rendah dan relevan merupakan cabaran utama sebelum melangkah ke penubuhan perniagaan sebenar. Usahawan lebih gemar menjana idea perniagaan yang memenuhi kehendak pelanggan namun melibatkan kos yang tinggi. Hasilnya perniagaan tersebut bertahan hanya bertahan dalam jangka masa yang singkat. Menurut kajian Gusniar et al. (2014), seseorang individu perlu lebih cenderung memulakan perniagaan yang menggunakan modal yang kecil, menjimatkan masa pengeluaran dan tenaga mahir. Seseorang individu yang baru menceburi bidang keusahawanan perlu memilih perniagaan kecil-kecilan dan perniagaan tersebut diuruskan dengan kos yang rendah berserta matlamat untuk membantu mengurangkan bebanan masyarakat (Faradillah, Samsudin , \& Ali, 2015). Namun Fuentelsaz et al. (2018) mempunyai perspektif yang berbeza dan mendapati kos yang rendah dalam memulakan perniagaan akan menghadkan pelbagai kos perbelanjaan awal dan memberi risiko kepada perniagaan untuk berkembang. Ini kerana keuntungan yang lumayan menjadi faktor pemilihan kerjaya keusahawanan berbanding menceburi bidang perniagaan yang memberi keuntungan yang rendah, namun usahawan hanya mengeluarkan modal yang rendah dan takut mengambil risiko.

\section{Komunikasi Interpersonal}

Secara umumnya, komunikasi interpersonal berfungsi sebagai alat pertukaran idea dan maklumat dengan tujuan mendapatkan keperluan tertentu dalam kehidupan seharian antara dua pihak (Mohd Asri, 2015). Dalam konteks keusahawanan, jaringan komunikasi yang erat antara dua pihak perniagaan menjadi asas kepada pembentukan dan perkembangan perniagaan baharu. Menurut Freudenberg et al. (2012) cabaran usahawan berkomunikasi secara interpersonal adalah daripada segi penyampaian idea dengan penuh keyakinan dan mendapat perhatian daripada pihak pelabur luar. Beliau juga menyifatkan usahawan mempunyai halangan untuk mendapatkan maklumat yang diperlukan dalam perniagaan jika gagal bersikap peka terhadap keperluan dan menerima maklum balas terhadap sesuatu perkara. Manakala kebaikan komunikasi interpersonal dalam perniagaan memberi kelebihan kepada seseorang usahawan untuk mengakses sumber yang mempengaruhi prestasi perniagaan melalui hubungan jaringan dengan pihak berkepentingan. Menurut kajian Natashadora (2013), penguasaan kemahiran komunikasi interpersonal dapat melahirkan seseorang individu yang berpotensi membentuk jaringan dengan entiti luar bagi tujuan perniagaan.

\section{Kemahiran ICT}

Teknologi telah mengubah persekitaran masyarakat yang lebih kondusif dan berdaya maju pada hari ini. Menurut kajian Suriatie dan Nor Aishah (2017) teknologi menjadi satu instrumen yang memudahkan aktiviti seharian dengan adanya jaringan jalur lebar berkualiti tinggi. Manakala 
penggunaan ICT dan internet kini lebih sinonim dengan bidang keusahawanan untuk melengkapkan aktiviti pemasaran seperti pengiklanan yang lebih terurus. Cabaran dilihat kepada kemahiran menguruskan perniagaan dengan mengaplikasi penggunaan komputer dan Internet. Ini kerana penglibatan akses Internet dan diuruskan dengan kemahiran ICT yang sedia ada dapat membantu usahawan mengenal pasti kehendak dan keperluan terkini masyarakat (Suriatie \& Nor Aishah, 2017; Ruziah Ali, 2011). Tambahan, Suriyani et al. (2017) juga menekankan faktor yang memenuhi keperluan afektif penggunaan ICT dalam perniagaan adalah mudah digunakan (easy to use), usahawan merasakan perbezaan yang ketara setelah menggunakan ICT dan akhir sekali proses penyampaian maklumat lebih afektif dengan bantuan ICT. Dengan ini jelas menunjukkan kemahiran ICT merupakan cabaran yang perlu dilalui usahawan kerana dapat membantu masa depan perniagaan.

\section{Metodologi}

Populasi kajian adalah seramai 39,140 pelajar (KPT, 2017) yang terdiri daripada pelajar sarjana muda, sarjana (Master) dan PhD di Universiti Kebangsaan Malaysia. Kajian ini menggunakan kaedah kuantitatif yang melibatkan 150 sampel pelajar tahun kedua dan ke atas yang telah mengikuti kursus keusahawanan. Seramai 90 pelajar Fakulti Ekonomi dan Pengurusan dan 60 pelajar daripada Fakulti Sains Sosial Kemanusiaan telah terlibat dalam kajian ini. Majoriti responden merupakan pelajar perempuan iaitu seramai 78 orang (52.0\%) dan selebihnya responden lelaki seramai 72 orang (48.0\%). Pemilihan sampel ini dibuat secara rawak mudah dan saiz sampel pula adalah mengikut penentuan saiz sampel Krejcie dan Morgan (1970).

Reka bentuk kajian ini berbentuk tinjauan yang menggunakan soal selidik sebagai instrumen kajian. Soal selidik yang dibina oleh pengkaji merupakan soal selidik yang diadaptasi dan diubahsuai daripada Nor Aishah (2007) iaitu soal selidik psikometrik indeks keusahawanan. Berdasarkan soal selidik Nor Aishah (2007), item-item yang dibina adalah untuk mendapatkan jawapan kepada tahap keinginan keusahawanan dalam kalangan pelajar universiti awam. Tambahan juga, soal selidik yang dibangunkan oleh Nor Aishah (2007) adalah berdasarkan teori psikologikal-ekonomi Davidson (1995) yang menekankan pendekatan proses untuk menganalisis sikap dan tingkah laku manusia terhadap sesuatu perkara khususnya pemilihan kerjaya.

Soal selidik yang dibangunkan mengandungi 3 bahagian utama. Bahagian A mengandungi item kos perniagaan, Bahagian B pula mengandungi item komunikasi interpersonal manakala Bahagian $\mathrm{C}$ ialah item kemahiran ICT. Instrumen yang dibina kemudiannya diberikan kepada dua orang pakar akademik yang mempunyai pengalaman luas dalam pendidikan keusahawanan bagi mendapatkan kesahan muka dan kesahan kandungan. Analisis data bagi kajian ini melibatkan penggunaan statistik deskriptif. Analisis data bagi kajian ini mengunakan Perisian Statistical Package For Social Science. Pengkaji menggunakan jadual interpretasi skor min yang diadaptasi daripada Norasmah (2002) bagi menganalisis data utama kajian iaitu elemen cabaran kerjaya keusahawanan atas talian.

\section{Dapatan dan perbincangan}

Dapatan kajian daripada analisis deskriptif menunjukkan setiap kompenan cabaran keusahawanan berada pada tahap tinggi. Melalui dapatan kajian, faktor kos perniagaan merupakan antara cabaran yang besar kepada pelajar dalam memilih kerjaya keusahawanan atas talian, ini kerana seramai 17 orang responden $(11.0 \%)$ bersetuju bahawa perniagaan atas talian sukar dikawal. Namun begitu, seramai 82 orang responden $(53.2 \%)$ sangat bersetuju bahawa perniagaan atas talian lebih murah 
berbanding perniagaan tradisional. Seterusnya bagi faktor komunikasi interpersonal pula, seramai 84 orang responden $(54.5 \%)$ bersetuju bahawa kemahiran menyampaikan idea-idea baru kepada rakan merupakan cabaran yang besar. Manakala 16 orang $(10.4 \%)$ responden kurang bersetuju terhadap kemahiran menyakinkan orang lain melalui penyampaian yang berkesan merupakan salah satu cabaran kepada mereka. Bagi faktor kemahiran ICT pula menunjukkan seramai 75 orang responden $(48.7 \%$ ) bersetuju bahawa kemahiran berinteraksi dengan komputer merupakan cabaran terbesar di dalam bidang perniagaan atas talian. Namun begitu, hanya 20 orang responden (13.0\%) lebih bersetuju bahawa penyertaan media massa memberikan cabaran yang agak besar. Ketigatiga faktor tersebut memainkan peranan penting dalam mencorakkan minat keusahawanan pelajar. Dapatan juga menunjukkan cabaran keusahawanan mencatatkan skor min pada tahap tinggi secara keseluruhan. Ini bermakna responden bersetuju bahawa faktor tersebut merupakan cabaran utama sebelum memulakan perniagaan.

Kemahiran menguruskan perniagaan dengan menggunakan kemudahan perkomputeran dan Internet meningkatkan kreativiti dan daya saing usahawan. Dapatan kajian menunjukkan kemahiran ICT merupakan cabaran paling besar terhadap pemilihan kerjaya keusahawanan atas talian. Selaras dengan kajian Suriatie \& Nor Aishah (2017) mendapati usahawan perlu melibatkan penggunaan Internet dan perlu menguruskannya dengan kemahiran ICT yang sedia ada namun pada individu yang kekurangan kemahiran tersebut akan mengalami kesusahan untuk mengenal pasti kehendak dan keperluan terkini masyarakat. Seterusnya kos perniagaan merupakan cabaran kedua paling mencabar sebelum memulakan perniagaan kerana pelajar mempunyai dana kewangan yang terhad. Namun kajian Fuentelsaz et al. (2018) menegaskan individu yang mempunyai kos yang rendah semasa memulakan perniagaan akan menghadkan pelbagai kos perbelanjaan awal dan mengagalkan usaha individu untuk mengukuhkan perniagaan baru. Manakala komunikasi interpersonal merupakan cabaran yang kurang memberi tekanan kepada individu untuk memulakan perniagaan atas talian. Menurut kajian Freudenberg et al. (2012) cabaran usahawan berkomunikasi secara interpersonal hanya pada teknik penyampaian idea dengan penuh keyakinan bagi mendapatkan perhatian daripada pihak luar.

\section{Kesimpulan}

Analisis kajian menunjukkan kos perniagaan, komunikasi interpersonal dan kemahiran ICT merupakan cabaran utama kepada pelajar dalam memulakan perniagaan atas talian. Keinginan memulakan perniagaan atas talian didorong oleh faktor penentu pemilihan kerjaya keusahawanan melalui penciptaan dan pembentukan sebuah organisasi perniagaan atau usaha meneroka peluang baru di pasaran. Melalui dapatan kajian, beberapa cadangan dapat dilaksanakan bagi mengatasi cabaran dalam kalangan pelajar untuk memulakan perniagaan agar mencapai hasrat kerajaan yang memberi tumpuan terhadap penguasaan teknologi moden. Dalam melaksanakan pembangunan keusahawanan, platform perniagaan atas talian dapat melahirkan usahawan yang berintegriti serta berpengetahuan dalam bidang teknologi bagi meningkatkan kualiti diri dan bersedia untuk bersaing dalam pasaran pada era globalisasi kini selaras dengan aliran perkembangan ekonomi negara (Kementerian Pendidikan Tinggi, 2015). Selain itu, perancangan aktiviti keusahawanan perlu diselaraskan agar pelajar bersedia menjana perniagaan yang lebih berinovasi. Melalui kekerapan aktiviti keusahawanan juga boleh memberi keuntungan kepada pelajar dari segi kewangan dan kemahiran. Oleh itu, inisiatif institusi pengajian memberi pendedahan awal kepada pelajar dalam bidang keusahawanan atas talian dapat mendorong kepada kejayaan perniagaan dan berdaya saing dengan produk tempatan serta antarabangsa. 


\section{Rujukan}

Faradillah, I., Samsudin , A., \& Ali, S. (2015). Penyertaan digital dan ciri keusahawanan dalam pemerkasaan usahawn di Malaysia. Jurnal Komunikasi, 241-256.

Fuentelsaz, L., Juan, P., \& Javier, M. (2018). Entrepreneurs and innovation: The contingent role of institutional factors. International Small Business Journal: Researching Entrepreneurship, 1-26.

Freudenberg, B., Brimble, M., \& Cameron, C. (2012). WIL and generic skill development: The development of business students' generic skills throughwork-integrated learning. AsiaPacific Journal of Cooperative Education, 12(2), 79-93.

Gusniar Nurdin, Geraldine, Chan, Sivapalan Selvadurai, \& Suraiya Ishak. (2014). Hubungan sosial dan perniagaan kecil-kecilan di Malaysia - tingkah laku inovatif usahawan wanita atas talian. Malaysian Journal of Society and Space, 10(6), 206-218.

Kementerian Pendidikan Tinggi. (2015). Pelan Tindakan Keusahawanan Intitusi Pendiidikan Tinggi 2016-2020. Putrajaya: Kementerian Pendidikan.

Kementerian Pendidikan Tinggi. (2017). Dasar Pembangunan Keusahawanan. Putrajaya: Kementerian Pengajian Tinggi.

Muhamad Amirul Fikri, \& Mohammad Mujaheed (2018). Faktor penglibatan dan cabaran wanita melayu dalam keushawanan di Malaysia. Jurnal Sains Kemasyarakatan dan Pembangunan. 101-115.

Mohd Asri, A. (2015). Hubungan kompetensi usahawan dan efikasi keusahawanan terhadap tingkah laku inovatif guru praperkhidmatan IPG. Universiti Teknologi Malaysia: Tesis Dr Falsafah.

Natashadora Muridan. (2013). Penguasaan kemahiran komunikasi interpersonal dalam kalangan pelajar tahun satu fakulti pendidikan teknikal dan vokasional di UTHM. Parit Raja: Universiti Tun Hussein Onn Malaysia.

Nur Yuhainis Ab Wahab, \& Shuhymee Ahmad. (2017). Hubungan antara penggunaan ICT dan prestasi perniagaan PKS di Malaysia. Journal of Global Business and Social Entrepreneurship (GBSE), 1(3), 218-226.

Norasmah, H. (2002). Keberkesanan Program Keusahawanan Remaja di Di Sekolah Menengah. Tesis Dr Fal.

Nor Aishah Buang. (2007). Draf Instrumen Psikometrik Indeks Keusahawanan Nor Aishah (PIKEN). Fakulti Pendidikan Universiti Kebangsaan Malaysia.

Ruziah Ali. (2011). Strategi e-pemasaran di dalam transformasi pemasaran penerbitan buku. journal of Human Capital Development, 4(1), 79-89.

Suriatie Mohd Yunus, \& Nor Aishah Buang. (2017). Pendekatan penggunaan medium epemasaran dalam kalangan usahawan wanita. Journal of Global Business and Social Entrepreneurship (GBSE), 1(1), 47-57.

Suriyani Muhamad, Noraida Hj Ali, \& Masita Abdul Jalil. (2017). A sustainable e-business model for rural women: a case study. Journal of Sustainability Science and Management 